\title{
An Automatic Device for the Addition of Precise Amounts of Radiolabelled Material to Cigarettes *
}

\author{
by A. Ringrose, F. E. H. Crawley and C. R. E. Coggins \\ Battelle, Geneva Research Centre, Geneva, Switzerland
}

\section{SUMMARY}

A microprocessor-controlled device for the spiking of cigarettes with variable amounts of radiolabelled material is described. Cigarettes can be spiked at rates in excess of $100 / \mathrm{min}$, compared with the very slow manual methods in existence. The deposition of the radiolabelled material $\left(\left[16,17-{ }^{14} \mathrm{C}\right]\right.$ dotriacontane $)$ is very reproducible with a coefficient of variation of around $3 \%$. The device is capable of injecting cigarettes of various physical configurations, and of producing variable distributions of the radiolabelled material along the tobacco rod.

\section{ZUSAMMENFASSUNG}

Es wird ein mikroprozessorgesteuertes Gerät beschrieben, mit dem radioaktiv markiertes Material $\mathrm{Zi}$ garetten in variabler Menge zugesetzt werden kann. Im Gegensatz zu den langsamen manuellen Methoden kōnnen über 100 Zigaretten in der Minute behandelt werden. Die Aufbringung des radioaktiv markierten Materials $\left(\left[16,17-{ }^{14} \mathrm{C}\right]\right.$ Dotriacontan) ist mit einem Variationskoeffizienten von ungefähr $3 \%$ gut reproduzierbar. Die radioaktiv markierten Stoffe kōnnen in Zigaretten verschiedener āußerer Form injiziert und entlang des Tabakstranges unterschiedlich verteilt werden.

\section{RÉSUME}

L'article décrit un appareil commandé par microprocesseur permettant l'adjonction aux cigarettes d'un produit

"Received: 27th January 1983 - accepted: 15th July 1983.

de marquage radioactif en quantités variables. Contrairement aux méthodes manuelles très lentes, cet appareil permet de traiter plus de 100 cigarettes à la minute. La pose de ce produit de marquage radioactif ([16,17- $\left.{ }^{14} \mathrm{C}\right]$ dotriacontan) jouit d'une bonne reproductibilité, caractérisée par un coefficient de variation d'environ $3 \%$. Les substances de marquage radioactif peuvent être injectées dans les cigarettes de diverses structures et l'on peut en faire varier la distribution le long du boudin de tabac.

\section{INTRODUCTION}

Data on the deposition of particulates is considered essential in the interpretation of rodent inhalation studies using cigarette smoke (1). The most widely used method of evaluating such deposition is the addition of $\left[16,17-{ }^{14} \mathrm{C}\right]$ dotriacontane into the tobacco rod of cigarettes and the exposure of rodents to the smoke using special smoking machines $(2,3)$. The determination of the level of radioactivity in respiratory tract tissues then gives an estimate of the amount of total particulate matter deposited.

The published method (4) of adding $\left[16,17-{ }^{14} \mathrm{C}\right]$ dotriacontane to cigarettes is slow, laborious and unreliable. We describe here a completely automatic device capable of spiking cigarettes at rates in excess of 100 per hour, with very high levels of reproducibility in terms of the amount of the radiolabelled material added. The device is controlled by a microprocessor unit which allows different distributions of the radiolabelled material to be made along the tobacco rod. Radiolabelled cigarettes are smoked in a modified Battelle Mark III smoking machine (5), capable of exposing 72 rodents simultaneously to diluted cigarette smoke. 


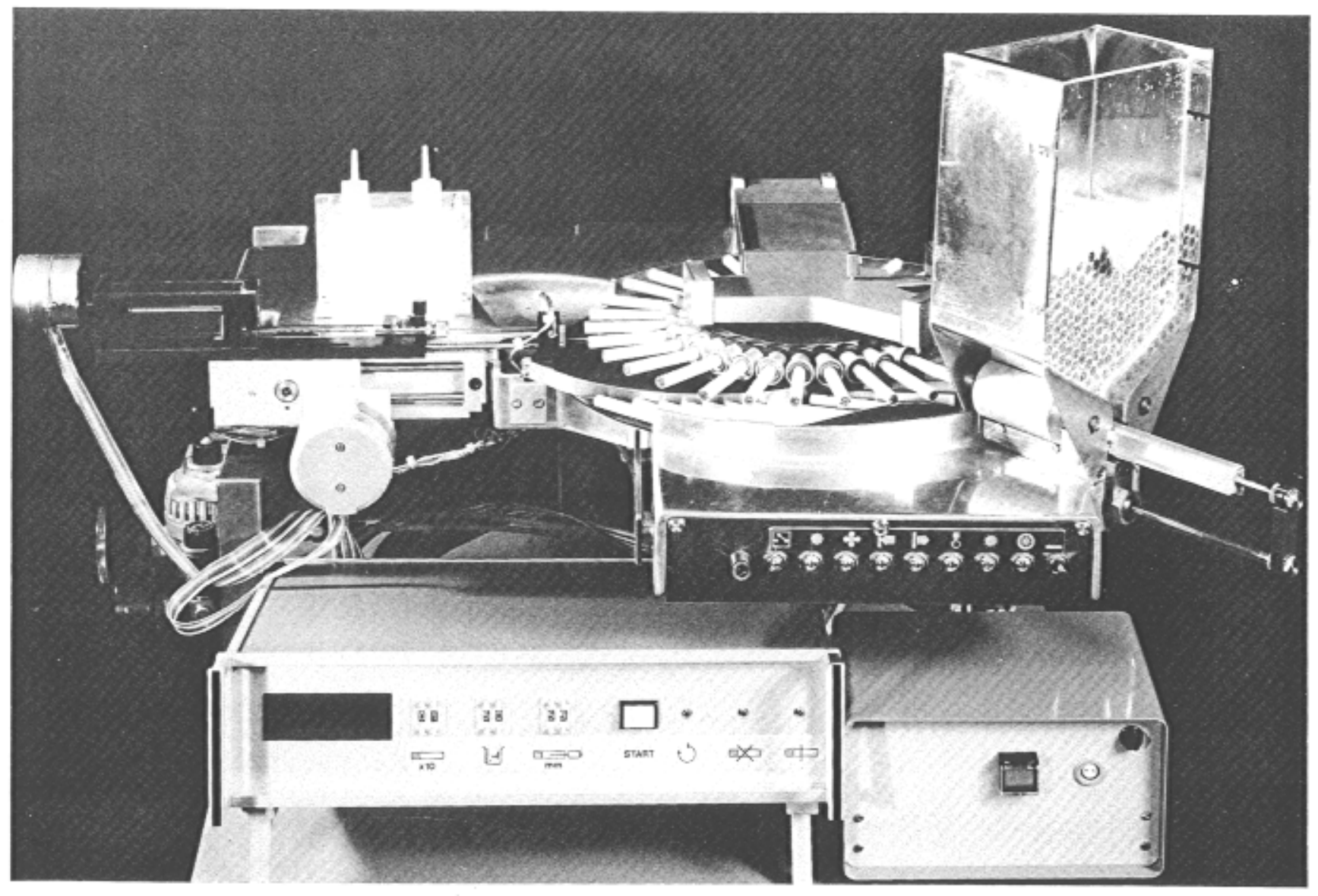

Figure 2. Close up view of the spiking unit.

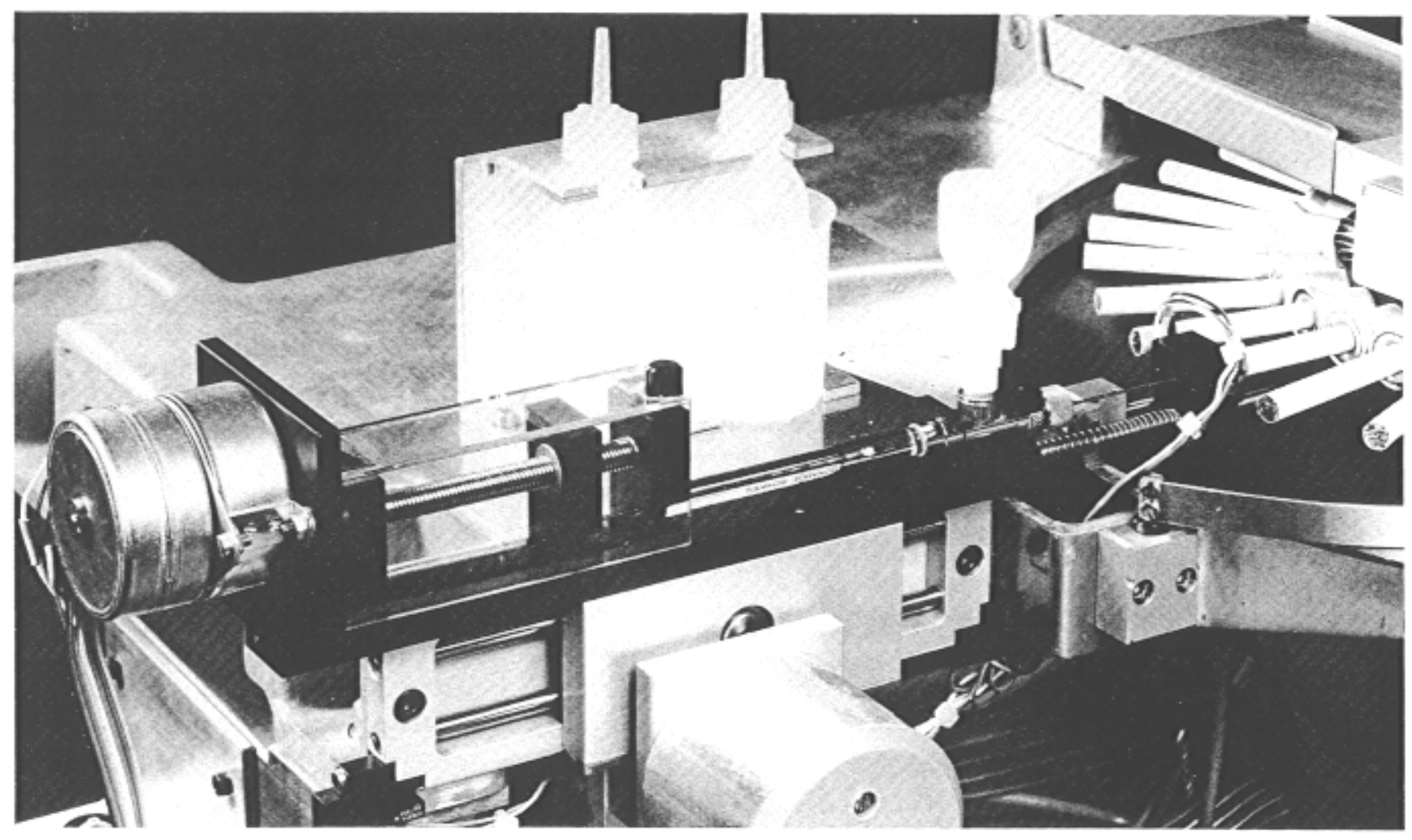


The spiking instrument consists of two distinct units:

- an automatic handling system, which transports the cigarettes consecutively to a fixed position for spiking,

- an automatic spiking device, which delivers the radiolabelled material in the required distribution along the tobacco rod.

Both units are controlled by a microprocessor which synchronizes the relative operations of each unit.

\section{Cigarette Handling}

The cigarette handling system uses the basic elements of the Battelle smoking machine (5). This system consists of a pneumatically operated loading device (fed by a 400-cigarette hopper) which loads the cigarettes consecutively into a rotary turret with a capacity of 30 cigarettes. The turret transports the cigarettes to the spiking position, and subsequently to a discharge station. A stepping motor is used to drive the turret, and is synchronized to the cycle of the spiking device, thereby presenting the cigarettes for injection at the required time interval. The cigarettes are injected with the radiolabelled material dissolved in a suitable volatile solvent (usually cyclohexane for $\left[16,17-{ }^{14} \mathrm{C}\right]$ dotriacontane). After spiking, the cigarettes are stored in the rotating turret for approximately 15 minutes during the spiking of subsequent cigarettes to allow evaporation of the volatile solvent. Prior to smoking experiments the cigarettes are maintained under controlled temperature and humidity conditions.

The cigarettes are automatically ejected from the turret, upstream of the loading station. Figure 1 gives an overall view of the apparatus.

\section{Spiking Device}

The operational mode of the spiking device (shown in Fig. 2) is as follows: a hollow needle, connected to a gas-tight microsyringe, pierces the tobacco rod longitudinally to a pre-determined depth. Centralization of the cigarette relative to the needle is ensured by a conical guide piece. A pre-programmed volume of the solution containing the radiolabelled material is drawn into the syringe, via a non-return valve, by a suction stroke of the syringe piston. The needle is then withdrawn from the tobacco rod at a controlled rate and the radiolabelled material simultaneously injected into the cigarette. For practical reasons, the hollow needle is actually withdrawn in a series of steps alternating with incremental injections of the solution.

The two essential movements of the spiking device, i.e. the withdrawal of the needle from the tobacco rod and the operation of the syringe piston, are controlled by two separate stepping motors. The relative movements of these motors define the amount and distribution of the radiolabelled material in the cigarette.

\section{Microprocessor Unit}

The electronic control unit comprises a single board microcomputer, interface, power supply and control panel, and is used to synchronize the movements of the spiking device, the rotary turret, the loading station and the ejection device. The various elements are operated consecutively, as simultaneous operation would have increased the development costs of the microprocessor unit.

Other functions and safety devices built into the microprocessor unit include a counter for the total number of spiked cigarettes, an automatic bypass of any unoccupied position in the turret, and an automatic closedown with audible alarm if a malfunction occurs in the cigarette loading. The detection of certain spiking errors and end of batch close-down is also incorporated.

Operating instructions are keyed into the unit via a control panel. These instructions comprise delivery volume, spiking length and the number of cigarettes to be spiked. The microprocessor then computes the operational sequences of the two motors to ensure the correct delivery volume and even distribution of the radiolabelled material along the tobacco rod. With minor adaptations of the microprocessor program it is possible to carry out more complex functions, such as profiled spiking along the tobacco rod.

\section{Delivery Volume}

As a result of the incremental character of the movements of the syringe piston and the needle, the delivery volume and distribution of the solution along the tobacco rod are not entirely linear over the operating range. In practice however, the inherent deliveryvolume deviations are not sufficiently significant to be of importance.

Over the normal working range of the instrument (50-100 microlitres), the theoretical delivery deviations vary by less than $2 \%$ of the set volume, depending on volume and spiking length. Figure 3 shows typical deviations in volume for $270 \mathrm{~mm}$ spiking length.

Flgure 3. Typlcal devlations in volume of cyclohexane

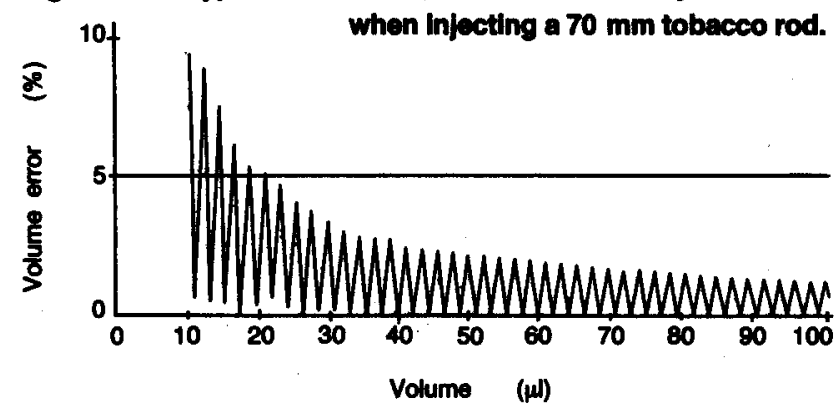


The delivery volume must be adjusted according to the length of the cigarette rod, the solubility of the material to be spiked and the volatility of the solvent. In the studies reported below a delivery volume of approximately $10 \mu$ of cyclohexane per $\mathrm{cm}$ of cigarette rod was used. No wetting of the cigarette wrapper was detected with this volume.

\section{SPIKING CHARACTERISTICS}

The performance of the instrument was tested by spiking cigarettes with $\left[16,17-{ }^{14} \mathrm{C}\right]$ dotriacontane and determining the distribution of the radioactivity along the tobacco rod. The instrument was subsequently used to spike batches of cigarettes to assess the reproducibility of the spiking process.

\section{Radiochemicals}

[16,17- $\left.{ }^{14} \mathrm{C}\right]$ Dotriacontane $(110 \mathrm{mCi} / \mathrm{mmol})$ was obtained from C.E.A. Saclay (France). The $\left[16,17-{ }^{14} \mathrm{C}\right] \mathrm{do}-$ triacontane was dissolved in cyclohexane to give a concentration of 3-8 $\mu \mathrm{Ci} / \mathrm{ml}$. The activity of the solution was confirmed before each spiking session by liquid scintillation spectrometry.

\section{Preparation of Cigarettes}

Six different types of cigarette (coded A-F) were used to evaluate the spiking characteristics. One of these (type A) was used in a detailed investigation of the distribution of the $\left[16,17-{ }^{14} \mathrm{C}\right]$ dotriacontane along the rod and the transfer into the wrapper. Types $B-F$ were used to determine the intersample coefficient of variation of the spiking process in the whole cigarette.

All cigarettes were kept at $20^{\circ} \mathrm{C}$ and $55 \%$ relative humidity for one week prior to spiking. The cigarettes were not weight or pressure-drop selected before use. All were $84 \mathrm{~mm}$ long ( $64 \mathrm{~mm}$ rod, $20 \mathrm{~mm}$ filter) with a $25 \mathrm{~mm}$ circumference. Approximately 100 cigarettes (type A) were spiked for the detailed investigation and 250 of each of types B-F for the other studies. Each cigarette was spiked with $58 \mu$ of the $\left[16,17-{ }^{14} \mathrm{C}\right]$ dotriacontane solution, with an injection length of $58 \mathrm{~mm}$. A different concentration of $\left[16,17-{ }^{14} \mathrm{C}\right]$ dotriacontane was used for each type of cigarette spiked. One cigarette was selected at random from each batch of ten or twenty cigarettes spiked in order to determine the radioactivity.

\section{Determination of Radioactivity}

In the detailed investigation of the distribution, the tobacco rods from eight cigarettes (type A) were sectioned into six equal portions. Each portion was extracted with toluene $(10 \mathrm{ml})$ by continuous shaking for
24 hours. Aliquots $(1 \mathrm{ml})$ of the extract were added to a scintillation fluid (15 ml of Dimilume, Packard Instruments Ltd.). The wrappers from 5 cigarettes (type A) were placed in vials containing Dimilume $(15 \mathrm{ml})$. Tobacco rods plus wrappers from the types B-F cigarettes were extracted as above with toluene $(20 \mathrm{ml})$. The toluene solution was centrifuged and $1 \mathrm{ml}$ aliquots were added to Dimilume $(10 \mathrm{ml})$. Triplicate samples of all extracts were prepared for the determination of radioactivity in a Beckman 8100 liquid scintillation system. Corrections for quench were made by the external standards method.

Trial experiments in which the $\left[16,17-{ }^{14} \mathrm{C}\right]$ dotriacontane had been extracted by the above method from tobacco rods plus wrappers had shown that the recovery of radioactivity was approximately $99 \%$ of the theoretical spiked radioactivity.

\section{Distribution of Radioactivity}

The variation of the $\left[16,17-{ }^{14} \mathrm{C}\right]$ dotriacontane deposition throughout the length of the tobacco rod (cigarette type $A$ ) is shown in the histogram in Figure 4. The spiking pattern is very uniform along most of the tobacco rod, with a lower deposition at each end. This was to be expected, as the length of the spike was $58 \mathrm{~mm}$ along the $64 \mathrm{~mm}$ rod. The total deposition of $\left[16,17-{ }^{14} \mathrm{C}\right]$ dotriacontane per tobacco rod was 0.277 $\pm 0.017 \mu \mathrm{Ci}$, with an overall coefficient of variation of $6.2 \%$. The theoretical deposition based upon the activity of the $\left[16,17-{ }^{14} \mathrm{C}\right]$ dotriacontane solution was $0.282 \mu \mathrm{Ci}$ per cigarette. The percentage of the radioactivity transferred to the wrapper was $1.4 \pm 0.4$.

Figure 4. Distribution of radloactivity along the tobacco rod of clgarettes splked with $[16,17-14 \mathrm{C}]$ dotrlacontane. The total radioactivity $(\mu \mathrm{Ci})$, standard deviations and coefficients of varlation for the six sections are given.

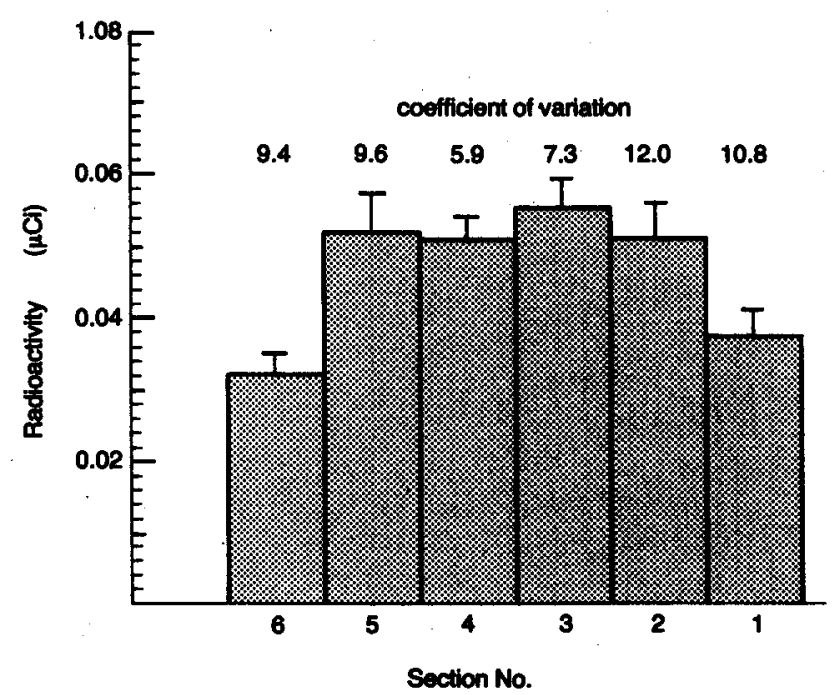

The results from the determination of the $[16,17-$ ${ }^{14} \mathrm{C}$ ]dotriacontane in the tobacco rods plus wrappers 
Table 1. The total radloactlulty determined in the tobacco rod plus wrapper after splking five different types of cigarette with $[16,17-14 \mathrm{C}]$ dotriacontane.

\begin{tabular}{c|c|c|c}
\hline \multirow{2}{*}{$\begin{array}{c}\text { Cigarette } \\
\text { type }\end{array}$} & \multicolumn{2}{|c|}{$\begin{array}{c}\text { Radioactivity per cigarette } \\
(\mu \mathrm{Cl})\end{array}$} & $\begin{array}{c}\text { Coefficient of } \\
\text { variation } \\
(\%)\end{array}$ \\
\cline { 2 - 3 } & mean & $\begin{array}{c}\text { standard } \\
\text { deviation }\end{array}$ & \\
\hline B & 0.396 & 0.012 & 3.0 \\
C & 0.532 & 0.016 & 3.1 \\
D & 0.394 & 0.016 & 4.0 \\
E & 0.403 & 0.009 & 2.2 \\
F & 0.567 & 0.017 & 3.0 \\
\hline
\end{tabular}

from cigarette types $\mathrm{B}-\mathrm{F}$ are summarized in Table 1. The mean coefficient of variation was $3.1 \pm 0.6 \%$, which is lower than that found in the detailed distribution study. This is presumably because the overall coefficient of variation quoted above $(6.2 \%)$ is a composite value obtained from the addition of the results from six separate analyses.

\section{REFERENCES}

1. Page, B. F. J., B. Woolsgrove, L. F. Chasseaud and R. Binns: Use of radioactive tracer techniques in investigations associated with cigarette smoking; Ann. occup. Hyg. 16 (1973) 409-416.

2. Reznik, G., N. Kmoch and U. Mohr: Inhalation experiments with ${ }^{14} \mathrm{C}$-labelled cigarette smoke, I. Determination of the effectiveness of two different smoking systems with labelled cigarettes; Toxicology 4 (1975) 363-371.
3. Pullinger, D. H., E. A. MacFarlane, T. H. Houseman and P. J. Simons: A new single animal smoking system for exposing rats and other rodents to cigarette smoke; J. Aerosol Sci. 8 (1977) 111-122.

4. Houseman, T. H., and E. Heneage: Studies of cigarette smoke transfer using radioisotopically labelled tobacco smoke constituents, Part I: The preparation of radioisotopically labelled cigarettes; Beitr. Tabakforsch. 7 (1973) 138-141.

5. Baumgartner, H., and C. R. E. Coggins: Description of a continuous-smoking inhalation machine for exposing small animals to tobacco smoke; Beitr. Tabakforsch. Int. 10 (1980) 169-174.

\section{Acknowledgements}

We thank André Bregnard and Jean-Lowis Maystre for the realization of the instrument and the microprocessor unit, and Roland Hyacinthe for the radiochemical determinations.

Autbors' address:

Dr. F. E. H. Crawley, Centre for Toxicology and Biosciences, BATTELLE, Geneva Research Centres, 7 , route de Drize, CH-1227 Carouge/Geneva, Switzerland. 